\title{
Sobre la revisión del carácter instrumental del acto administrativo
}

\author{
José Luis Meilán Gil \\ Catedrático de Derecho Administrativo \\ Universidad de A Coruña \\ Ex Consejero electivo de Estado
}

\begin{abstract}
SUMARIO: I. PLANTEAMIENTO. II. SILENGIO NEGATIVO: NATURALEZA Y GENERALIDAD. III. SILENCIO POSITIVO: NATURALEZA Y EVOLUCIÓN. IV: UNA CONSTRUCGIÓN PROGESALISTA DEL SILENCION ADMINISTRATIVO. V. LA INACTIVIDAD MATERIAL DE LA ADMINISTRACIÓN. VI. ABANDONO DEL ACTO ADMINITRATIVO PREVIO: EL GONTROL A POSTERIORI. VII. A MODO DE GONGLUSIÓN.
\end{abstract}

\section{RESUMEN:}

El trabajo analiza el silencio administrativo (negativo y positivo), la inactividad material de la Administración y el abandono de la autorización administrativa que se sustituye por declaraciones de los ciudadanos y el control a posteriori, de acuerdo con Directiva de servicios de la Unión Europea. La tesis que se defiende pretende superar la visión que tradicionalmente ha acompañado a las explicaciones del silencio administrativo sugiriendo un nuevo planteamiento en el que el acto administrativo pierde protagonismo en favor de una buena administración.

Palabras clave: Acto administrativo. Silencio administrativo. Inactividad. Autorización. Servicios. Buena administración.

\section{ABSTRACT:}

The paper looks at the administrative silence, both negative and positive, the material inactivity of the Public Administration, and the abandonment of an administrative authorization according to a Directive of European Union to improve services in the market. The author attempts to overcome the traditional view that has accompanied the explanations on the administrative silence under the administrative act preeminence suggesting a new approach 
in which the administrative act loses leading role and good Governance gains prominence.

Key words: Administrative Law. Administrative Silence. Inaction. Authorization. Market. Good Governance.

\section{PLANTEAMIENTO}

El acto administrativo ocupa un lugar central en la formación y desarrollo del Derecho administrativo no anglosajón. Lo corrobora el testimonio de autores tan significativos como Otto Mayer ("El Rechtstaat se perfecciona por el acto administrativo") y Maurice Hauriou ("El Derecho administrativo francés ha hundido su raíz jurídica en el acto de administración. Todo se ha concentrado en el acto"). Sobre su configuración como categoría jurídica, su origen y entendimiento, tanto en los diferentes ordenamientos jurídicos, como en sede doctrinal me he ocupado en otro lugar al que me remito. ${ }^{1}$ Tiene desde su origen, tanto en Francia como en Alemania, un carácter instrumental que permanece en el Derecho administrativo europeo continental y latinoamericano que a contrario sensu revela su no explícita aceptación en el Common law.

Como sucede con otras instituciones de Derecho administrativo la funcionalidad del acto administrativo está condicionada por un contexto histórico, en el que concurren circunstancias políticas e ideológicas, que con el devenir del tiempo se consolidan y pueden no constituir ya, al menos en parte, un referente idóneo. Una reflexión de este tipo es conveniente en un Derecho al que, como vengo sosteniendo y desarrollando desde hace muchos años, le es consustancial "su servidumbre respecto de la oportunidad y su apego a la política"2, su naturaleza de Derecho de realización del interés general que justifica la organización de la convivencia. ${ }^{3}$

¿Hasta qué punto han de permanecer postulados nacidos y sostenidos en un contexto histórico diferente al actual? La reflexión, que abarca a las diferentes categorías e instituciones del Derecho administrativo, se circunscribirá en esta ocasión a algunos aspectos de la funcionalidad instrumental del acto administrativo.

${ }^{1}$ Cfr. MEILAN GIL, José Luis, Categorías jurídicas en el Derecho administrativo, Cfr. MEILAN GIL, José Luis, El proceso de la definición del Derecho administrativo, ENAP, Madrid Iustel, 2011, pp.105 y ss.

${ }^{2}$ Cfr. MEILAN GIL, José Luis, El proceso de la definición del Derecho administrativo, ENAP, Madrid, 1967, y Administración Pública en perspectiva, Universidade da Coruña, A Coruña, 1996, pp. 25 y ss.

${ }^{3}$ Cfr. MEILAN GIL, José Luis, Categorías... pp. 173 y ss. 
Una peculiaridad del Derecho administrativo es, precisamente, la existencia de un acto para la aplicación de la norma, trátese de la ley o de un reglamento o disposición general. Entre la norma y el ciudadano se interpone, en muchas ocasiones, la Administración, lo que no sucede en otras partes del ordenamiento jurídico, singularmente en el Derecho privado. ${ }^{4}$ Como gráficamente dejó expresado Von Stein, la Administración pública es el "Estado en acción". En una materia tan amplia y, a menudo tan variable como es el ámbito en que opera, que resiste a la codificación, lógica y natural en otras partes del ordenamiento jurídico, el acto es un instrumento idóneo para la realización del Derecho.

Sucede en todos los sistemas jurídicos, con independencia del nombre que se le dé. En realidad, el acto administrativo es una generalización de actos de la misma naturaleza. Tiene su razón de ser en el origen histórico de la categoría al formularse la separación de Poderes por los revolucionarios franceses con la finalidad política de consolidar la revolución ${ }^{5}$. Sirve como referencia unitaria en leyes generales de procedimiento administrativo y de la jurisdicción contencioso-administrativa. Sin acudir a esa generalización, existen en el Derecho norteamericano, como pone de manifiesto la Administrative Procedure Act ${ }^{6}$.

Se considere el acto administrativo, en sentido estricto o simplemente como tal, puede admitirse sin mayor discusión que se trata de un acto unilateral de quien tiene una potestad o poder reconocido por el ordenamiento jurídico. Para decirlo con la expresiva formulación francesa se trata de una decisión exécutoi$r e$ que, de una u otra manera, se recoge en ordenamientos continentales europeos y latinoamericanos, con sus notas de ejecutividad, presunción de validez o ejecución forzosa. Sin entrar en discusiones doctrinales acerca de ellas, el acto administrativo es un instrumento jurídico de intervención de la Administración en el ámbito que corresponde a los ciudadanos. Dado que la Administración, para servir a los intereses generales debe actuar con sometimiento pleno a la ley y al Derecho, según la feliz expresión del artículo 103,1 de la CE española, el acto administrativo debe estar sujeto al control judicial.

\footnotetext{
${ }^{4}$ Cfr. MEILAN GIL, José Luis, La distinción entre norma y acto administrativo, ENAP, Madrid, 1967

${ }^{5}$ Cfr. MEILÁN GIL, José Luis, Categorías... pp. 109 y ss. El reconocimiento de que se trataba de razones políticas y no teórico-dogmáticas se encuentra también en LAFERRIÈRE, Traité élémentaire de Droit administratif, París, 1933, p. 602.

${ }^{6}$ Definiciones de order, licence, adjudication.
} 
La relación del acto administrativo con la revisión judicial está en el origen mismo del acto administrativo y del contencioso-administrativo en Francia ${ }^{7}$ y se consolidará con la exigencia del acto préaIable para acceder a aquel ${ }^{8}$, que explica el término recurso para la acción del particular y que se ha mantenido en el Derecho español.

Significativa es esa relación en el Tratado de la Unión Europea, habida cuenta de que el Derecho comunitario ha venido a ser un meeting point de tradiciones jurídicas diferentes. ${ }^{9} \mathrm{El}$ artículo 230 se refiere a que "el Tribunal de Justicia controlará la legalidad de los actos -entre otros- del Consejo y de la Comisión y del BCE que no sean recomendaciones o dictámenes" y "a tal fin será competente para pronunciarse sobre los recursos", por los motivos allí enunciados que los vician. En su párrafo cuarto, en concreto, señala que "toda persona física o jurídica podrá interponer... recurso contra las decisiones de las que sea destinataria". Se trata de un recurso de anulación del acto o decisión (artículo 231). Aunque ese recurso sea el más usado, no siempre es necesaria la existencia de un acto previo, ya que está previsto un recurso de omisión con base en los artículos 232 y 233.

Si bien ya la ley española de la jurisdicción contencioso-administrativa de 1956, de naturaleza claramente judicial, no admitió las dos clases de recurso de anulación y de plena jurisdicción del Derecho francés, siguió considerándose aquella, como revisora del acto. La evolución respecto del entendimiento del contencioso-administrativo podría sintetizarse en los siguientes pasos: se abandona el acto administrativo como objeto del recurso o proceso al acto; el acento se pone sobre la pretensión, que no era solo de nulidad, primero con ocasión de un acto; después de la Constitución de 1978 (artículo 106) "en relación con la actuación de las Administraciones Públicas sujetas al Derecho administrativo" (artículo 1 de la LJCA) en la que cabe la no actuación debida.

Ese "comportamiento" positivo o negativo reconduce, en términos estrictamente jurídicos, al ejercicio de la potestad. Desde esta perspectiva se produce

\footnotetext{
${ }^{7}$ Cfr. MEILÁN GIL, José Luis, Categorías... pp. 113-116. Hauriou dirá enfáticamente refiriéndose al Derecho administrativo "lo que en él hay de irreductible es el proceso al acto y la competencia administrativa". Cfr. Obra escogida, IEA, Madrid, 1976, p. 64.

8 Íbidem, pp. 128 -129 y referencia a G. VEDEL y P. DEVOLVÉ, Droit administratif, PUF, París, 1990, pp. 240-242.

${ }^{9}$ Cfr. MEILÁN GIL, José Luis, La estructura de los contratos públicos, Iustel, Madrid, 2008, pp. 93 y ss.
} 
un encuentro con el common law. En éste, tanto en el Reino Unido como en los EEUU, lo fundamental es que el power se ejercite dentro de los límites establecidos legalmente, de otro modo se actuaría ultra vires, sin entrar ahora en el alcance del principio y su relación con el de reasonableness ${ }^{10}$

Poner el acento en la potestad permite explicar con naturalidad el acceso a la jurisdicción contencioso-administrativa de actos que proceden de entes que no forman parte de la Administración pública como organización -trátese de parlamentos o tribunales u otros entes- y que no corresponden a la actividad definidora de su función. Son actos administrativos, aunque no sean actos de la Administración. ${ }^{11}$

La funcionalidad del acto administrativo, obviamente, no se limita a ser instrumento que hace posible el control judicial de la Administración. Como se apuntó anteriormente lo es de intervención, caso típico de licencias y autorizaciones varias que han sido manifestación de un amplio poder de policía que no es del caso desarrollar ${ }^{12}$, y que es igualmente perceptible en el common law americano de la regulación, en el que las Agencias tienen power over business practices ${ }^{13}$

Para verificar la revisión posible del carácter instrumental del acto que se desprende de lo expuesto se elegirán como temas testigos entre otros posibles ${ }^{14}$ la ficción del acto en el silencio administrativo ${ }^{15}$, el acceso al contencioso sin

${ }^{10}$ Cfr. W. WADE, Administrative Law, Clarendon Press, Oxford, 1989, Es el primary purpose of administrative law (p.5), the central principle of administrative law (p. 39).

B. SCHWARTZ, Administrative Law, Little, Brown and Company, Boston, 1984: the basic doctrine of administrative law, as of corporation law, is the doctrine of ultra vires" (p. 153).

${ }^{11}$ Cfr. Artículo 1, 3 LJCA; artículo 230 del tratado de la UE. Desde otro punto de vista, la composición y funciones de un ente permite considerarlo "poder adjudicador" a los efectos de contratos públicos "aunque no esté formalmente integrado en la Administración del Estado" STJCE de 20 de septiembre de 1988, asunto 31/87, Gebroeders Beentjes BV / Estado de los Países Bajos.

12 Cfr. MEILÁN GIL, José Luis "Sobre la determinación de la autorización y concesión” RAP, 71, 1973, pp. 80 y ss. con revisión de la doctrina tradicional entonces vigente. Prólogo a AMOEDO SOUTO, C. A. Poder policial y Derecho administrativo, Universidade da Coruña, 2000. LAGUNA DE PAZ, J.C., La autorización administrativa, Thomson-Civitas, Cizur Menor, 2006

${ }^{13}$ Cfr, B. SCHWARTZ, op. cit. pp. 15 y ss.

${ }^{14}$ En ocasiones se ha instrumentalizado el acto procesalmente para impedir el acceso a la jurisdicción al considerarlo una norma o para negar su consideración como norma con esa misma finalidad en distintos momentos de la configuración del Estado. Cfr MEILÁN GIL, J.L., La distinción entre norma y acto administrativo, ENAP, Madrid, 1967.

${ }^{15}$ La ley de 17 de julio de 1.900 introduce en Francia el silencio administrativo, que como reconoce Hauriou "asimila a una decisión denegatoria y, por tanto, a un acto", con lo que "el proceso al acto se ha hecho poco menos que perfecto". Cfr. Obra escogida... pp. 55 y 64. 
necesidad de acto administrativo previo, el debilitamiento de la autorización administrativa y la sustitución del carácter imperativo del acto administrativo por otras soluciones de soft law.

\section{SILENGIO NEGATIVO: NATURALEZA Y GENERALIDAD}

No es preciso desarrollar ahora por extenso el régimen jurídico del silencio administrativo y su construcción doctrinal con numerosa bibliografia ${ }^{16}$ producida en diferentes etapas de la orientación ideológica del Estado ${ }^{17}$ (Su evolución legislativa y el reflejo doctrinal se contienen en STS de 6 de octubre de 2003 y STS de 17 de noviembre de 2011). Bastará con subrayar algunas notas.

Ante todo conviene recordar que el silencio administrativo es reconducible a lo que con mayor propiedad se reconoce como inactividad formal: "la pasividad de la Administración, dentro de un procedimiento, es la simple no contestación a una petición de los particulares" que se distinguiría de la inactividad material, "una pasividad, un no hacer de la Administración en el marco de sus competencias ordinarias", ${ }^{18}$ dualidad que me parece más certera que la apelación a la metáfora del silencio.

Los efectos desestimatorios del silencio negativo se justifican como decía la Ley de la Jurisdicción contencioso-administrativa (LJCA) de 1956 "como garantía para los administrados frente a las demoras de la Administración". Se trataba de facilitar el acceso a la jurisdicción sin esperar a que la Administración dictase un acto expreso. En el mismo sentido se manifestaba la Ley de Procedimiento administrativo (LPA) de 1958 (art. 94): petición, no notificación de la decisión en el plazo de tres meses y, denunciada la mora, podía considerarse desestimada la petición al efecto de deducir frente a esa denegación presunta el correspondiente recurso administrativo o jurisdiccional o esperar la resolución expresa. Esa tesis es asumida por una jurisprudencia consolidada. El silencio negativo es "una mera ficción legal".

16 Además de obras generales cfr. GARCÍA-REVIJANO GARNICA, E. El silencio administrativo en el Derecho español, Civitas, Madrid, 1990. Aunque pueden citarse otros precedentes posibles, la influencia francesa ha sido incuestionada.

${ }^{17}$ Cfr. GARCÍA PÉREZ, M. "El tiempo y el Derecho administrativo. De la ley de procedimiento a la Directiva de Servicios" en La Administración Pública entre dos siglos, INAP, Madrid, 2010.

18 Cfr. NIETO A, "La inactividad de la Administración y el recurso contencioso administrativo", $R A P, 37,1962$. 
Lo fundamental es proporcionar una facultad de reacción del particular. La concepción del contencioso administrativo llevó a considerar la ficción de un acto y a que se llegase en algún momento a hablar de acto tácito frente al auténtico acto que es el expreso. Daba pie para esa consideración el lugar que el silencio ocupaba en la ley no procesal: el modo de terminar un procedimiento administrativo.

La referencia al acto se manifestó en alambicadas construcciones para determinar el dies a quo a partir del cual pueden interponerse los recursos, llegando a utilizar para ello lo dispuesto para notificaciones defectuosas o incompletas de los actos expresos. Así lo corroboró el Tribunal Constitucional, para que la Administración, por su inactividad, no se colocase en "mejor situación que si hubiera efectuado la notificación con todos los requisitos legales". (Ad exemplum, STC 149/2009, ente otras). La ficción es indudable. Se utiliza la notificación de un acto expreso para un acto que no se ha dictado, cuyo contenido esencial se da por supuesto. Para conseguir el objetivo que persigue no es necesaria la ficción de un acto o, si se prefiere subrayar más la contradicción, de un acto ficticio, como se razonará posteriormente.

La insatisfacción de esa tesis, llevada hasta sus extremos, se manifiesta en la jurisprudencia según la cual, aun reconociendo que "en los supuestos de silencio administrativo, el denominado acto presunto no es sino una ficción porque realmente no existe tal acto administrativo,... la denuncia de la mora... no es sino un trámite para que quede libre la vía del recurso administrativo o judicial, cuyo incumplimiento es subsanable... y por consiguiente su falta no justificaría la inadmisión de la acción ejercitada" ( STS de 20 de abril de 1996, con cita de otras).

La cuestión se relaciona con el plazo para interponer el recurso a partir del dies a quo. Ha dado lugar a una jurisprudencia contradictoria y al debate doctrinal $^{19}$, alimentado por el derecho fundamental a la tutela judicial efectiva (art 24.1 CE). Desde este derecho fundamental, por qué el particular no habría de poder esperar a que la Administración dictase el acto expreso para interponer el recurso contencioso. Desde la interpretación literal del artículo 46,1 de la LJCA que fija en seis meses el plazo con referencia al día siguiente en que "se produzca el acto presunto", superado el plazo el recurso no sería admisible por en-

${ }^{19}$ Cfr. ESCUIN PALOP, V. y BELANDO GARIN, B., Los recursos administrativos, Thomson Reuters, Cizur Menor, 2011. 
tender que se había consentido, ya que la inadmisión del recurso opera en relación con actos "confirmatorios de actos consentidos por no haber sido recurridos en tiempo y forma" (art. 28 de la LJCA).

El Tribunal Constitucional, de cuya doctrina se hace un amplio resumen en STS de 17 de noviembre de 2011, con razón ha declarado que "deducir de ese comportamiento pasivo el referido consentimiento con el contenido de un acto administrativo en realidad no producido... supone una interpretación irrazonable que choca frontalmente con el derecho a la tutela judicial" (STC 39/ 2006). No se confirma lo que no existe, aunque se hable de "desestimación presunta", si bien el razonamiento no acaba de liberarse de la inercia del acto. La ficción, en que se funda el silencio administrativo negativo, se convierte en un acto, una incongruencia.

\section{SILENGIO POSITIVO: NATURALEZA Y EVOLUGIÓN}

El silencio negativo era la regla general. Sólo en algunos casos limitados se admitía el silencio administrativo positivo. Existía práctico consenso doctrinal en que en este último caso el silencio implicaba un auténtico acto, que se denominó presunto, con diferencias de régimen jurídico.

La orientación legislativa cambió en una muy discutida ley de 1992 (30/1992 de 26 de diciembre) con el gobierno socialista en el poder. Se puso el acento en la obligación de la Administración de resolver expresamente las peticiones de los particulares. Su exposición de motivos habla de superar la doctrina del llamado silencio administrativo. Según sus propias palabras "el carácter positivo de la inactividad de la Administración es la garantía que se establece cuando no se cumple el verdadero objetivo de la Ley: que todos los ciudadanos obtengan respuesta expresa de la Administración y, sobre todo, que la obtengan en el plazo establecido".

La orientación de la ley tenía un plausible objetivo moralizador de la Administración, que debe actuar dando la debida respuesta explícita a las peticiones de los particulares. Y así se ha reconocido en algunas sentencias del Tribunal supremo que reproducen frases de la exposición de motivos de la ley, que invoca la primacía de la eficacia sobre el formalismo. "El silencio, positivo o negativo- se dirá- no es sino el remedio contra el fracaso del cumplimiento por la Administración de su obligación de resolver" (STS de 28 de enero de 2009 recurso en interés de la ley). 
La articulación legal de ese propósito no fue satisfactoria, entre otras razones por la pretendida previsión, aunque negada en la realidad, de erigir el silencio administrativo en regla general. "Una trampa gigantesca" se llegó a decir en la doctrina científica que mayoritariamente vapuleó la reforma. Esa aparente pretensión quedaba, por ejemplo, devaluada al afirmar que existía silencio positivo "en todos los casos, en cuya normativa de aplicación no se establezca que quedarán desestimadas si no recae resolución expresa (art. 43,2). Así se hizo en numerosas ocasiones por vía reglamentaria, aprovechando la adecuación de los procedimientos imperada por una disposición adicional de la referida Ley.

De otra parte, no quedaba ya duda alguna de que para el legislador el silencio generaba un acto administrativo, que se denominó presunto, equiparable al acto expreso con los efectos correspondientes. A ello contribuía la exigencia de la "certificación expedida por el órgano competente que debió resolver expresamente el procedimiento" (art. 44.2), bastando la exhibición de haberla pedido si la Administración no la expidiese. La vinculación del silencio al acto quedaba reforzada.

El negativo recibimiento de la ley por la doctrina científica y las dificultades prácticas que generaba motivaron su reforma, coincidiendo con un cambio de gobierno, en esta ocasión del Partido Popular, en 1999. Así se reconoce en la exposición de motivos de la ley. Se trataba de modificar los aspectos más problemáticos "fundamentalmente, la regulación del silencio administrativo". Se acepta lo que era opinión mayoritaria: "La desestimación por silencio administrativo tiene los solos efectos de permitir a los interesados la interposición del recurso administrativo o contencioso administrativo correspondiente" La estimación, en cambio tiene "a todos los efectos la consideración de acto administrativo finalizador del procedimiento" (art. 43,3) Así se reconoce como doctrina unánime en la jurisprudencia: ".surge el silencio con las características y efectos de un auténtico acto administrativo" (STS de 27 de abril de 2009).

Permanece la vinculación del silencio al acto, aunque se haya flexibilizado la acreditación del acto presunto que puede realizarse por cualquier medio de prueba admitido en Derecho. Esa vinculación se reafirma al determinar que el acto expreso que hay obligación de dictar solo puede ser confirmatorio del acto presunto. En el caso del silencio negativo, la obligada resolución puede ser distinta a lo por él significado. Se trataría de una anómala revocación in melius, de un acto ficticio. 
Se mantiene la impresión de generalidad del silencio administrativo positivo, así reconocida por la jurisprudencia (ad exemplum, STS de 30 de septiembre de 2009), que la realidad desmiente, al decir que los interesados podrán entender estimadas por silencio administrativo sus solicitudes "en todos los casos, salvo que una norma con rango de ley o norma de Derecho Comunitario Europeo establezca lo contrario", además del ejercicio del derecho de petición y los procedimientos en los que la estimación implicase transferencias de facultades relativas al dominio público o al servicio público, o de impugnación de actos y disposiciones.

Por tanto, una ley estatal o autonómica, de acuerdo con la distribución de competencias del Estado compuesto, puede impedir el juego del silencio positivo. Se zanja así la problemática surgida en torno a los actos presuntos contrarios al ordenamiento jurídico en materia urbanística donde el texto refundido de la ley de suelo de 2008, como su precedente ley de 1992, dice que "en ningún caso podrán adquirirse por silencio facultades o derechos que contravengan la ordenación territorial o urbanística" (Cfr. STS de 28 de enero de 2009 dictada en interés de la ley). Se pone en cuestión no solo la virtualidad del llamado silencio administrativo positivo, sino incluso su real existencia, sobre lo que se razonará más adelante.

El desiderátum de considerar el silencio positivo como regla general debería conducir a una interpretación en favor del mismo. Por eso era lógico que no pudiese "ser objeto de interpretación extensiva ni analógica" (STS de 22 de septiembre de 1994) el silencio negativo, considerado como la excepción. En ese caso la interpretación debería ser restrictiva. Esa interpretación no sería aplicable al silencio positivo considerado como regla general. En esa línea se ha llegado a sostener en la jurisprudencia que "al no encontrarse recogido el supuesto" en la norma que recoge aquellos en los que se establece el silencio negativo, no puede negarse la existencia del silencio positivo, recayendo en la Administración la carga de desvirtuarla (STS de 9 de diciembre de 2010, $\mathrm{RJ} / 2010 / 8912$ ).

En favor de esa tesis se ha manifestado la jurisprudencia en relación con el silencio de la Administración en cuanto a la petición de tasación del bien por el titular expropiado, al analizar el artículo 74 del Reglamento de expropiación forzosa y artículos correspondientes de la ley. La falta de respuesta constituye un supuesto de silencio positivo al no aparecer entre los exceptuados en el artículo 43 de la ley 30/1992, y no de silencio negativo entendiéndose con él la desestimación de la hoja de aprecio de retasación, contra la cual sostenía la Administración que obligaba a interponer recurso contencioso-administrativo. El tribunal 
razona "si el silencio es positivo y en su virtud procede la retasación interesada, ningún sentido tiene la interposición de un recurso contencioso-administrativo como necesario para hacer efectivo aquello que ya otorga sin necesidad de pronunciamiento judicial, que es la posibilidad de acudir directamente al Jurado ante la inactividad de la Administración en la fijación de un nuevo justiprecio por retasación, pues el instituto del silencio administrativo es una ficción legal establecida siempre en beneficio del particular frente a una Administración que utiliza el privilegio del acto previo para impedirle el ejercicio de un derecho o para cerrarle el paso a la vía revisora”. En ese caso supone la estimación de la retasación propuesta. (STS de 21 de diciembre de 2011 (rec, 4943/2008).

No siempre los tribunales se orientan en esa dirección. Un caso concreto ilustrará la contradicción.

El artículo 8,3 del Decreto 302/2001 de la Xunta de Galicia, que recoge los distintos efectos del silencio, reconoce el carácter negativo del silencio en el caso de solicitudes no contestadas sobre aprobación de planes eólicos empresariales. No se dice nada respecto de solicitudes de ampliación o prórroga del plazo de los ya aprobados, que era el objeto litigioso.

La Administración autonómica sostuvo que no es de aplicación el silencio positivo porque no cabe cuando la estimación supondría "transferir facultades relativas al dominio público o al servicio público". Tal invocación al dominio público es improcedente porque no existe esa transferencia, como se deduce de la STS de 30 de enero de 2007 (rec. 3370/2004): "los vientos... entran dentro de la categoría de las res communis ómnium, las cosas que son comunes a todos los hombres e inapropiables por naturaleza", tesis recogida en la STSJ de Galicia de 22-10-2008 (rec. 7092/2008).La improcedencia de la invocación del servicio público queda de manifiesto en la inequívoca exposición de motivos de la Ley 54/1997 de 27 de noviembre del sector eléctrico: "se abandona la noción de servicio público". Por una y otra razón los parques eólicos están sometidos a autorización y no a concesión.

La Administración autonómica mantuvo también que la Ley de Galicia 6/2001 de 29 de junio de adecuación a la Ley 4/1999 de 13 de enero al reconocer como negativo el silencio en los procedimientos de aprobación de planes eólicos y de autorización de instalaciones de un parque, ese efecto se aplica también a "la ampliación del plazo de ejecución". Esa interpretación va en contra del pretendido carácter general del silencio administrativo. De una parte, la ampliación solicitada se refiere a un plan ya aprobado, que no se identifica con la aprobación ex novo de otro y, además, un plan no es un parque. El 
parque es una instalación, un establecimiento industrial de producción de energía eléctrica, como corrobora la Ley 54/1997 del sector eléctrico. El plan, en cambio, es un proyecto de investigación.

El proclamado carácter general del silencio administrativo no debiera amparar estas interpretaciones restrictivas. En caso de duda debería estarse a favor del silencio administrativo positivo, si hemos de creer al legislador. El silencio administrativo es un instrumento procesal creado en beneficio del interesado y como tal no puede beneficiar a la Administración que lo provoca. Dicho con expresivas palabras de una STS de 17 de abril de 1990, ponente el profesor González Navarro, el silencio "no supone una autorización para no resolver cuando le venga en gana".

La no inclusión por una Administración de los procedimientos en los que el silencio tiene carácter negativo, desestimatorio, es suficiente para reconocer la regla general del silencio administrativo. En ese sentido tiene lógica, por ejemplo, que se prevea expresamente el silencio negativo para el otorgamiento de concesiones mineras y que al no figurar entre los supuestos en que se produce ese silencio la prórroga de ellas (anexo II de la ley 6/2001 de 29 de junio de Galicia) se entienda obtenida por silencio administrativo positivo. La prórroga no es una nueva concesión y la ponderación de intereses, por ejemplo por razones medioambientales, no tiene que volver a realizarse. La evaluación ya había sido realizada positivamente para el otorgamiento de la concesión.

Con motivo de la transposición al ordenamiento jurídico español de la Directiva 20067/23/CE del Parlamento y del Consejo de 12 de diciembre relativa a los servicios en el mercado interior se aprobó la ley 25/2009 de 22 de diciembre conocida como "ley ómnibus" por la repercusión que tuvo en numerosas normas. El objetivo de la Directiva, que como todas las de la UE vincula a los Estados miembros sin prejuzgar el tipo de norma a dictar, es la consecución de un real y efectivo mercado interior, de acuerdo con preceptos y principios del Tratado de la Unión, que implica un espacio sin fronteras interiores en el que esté garantizada la libre circulación de servicios. En concreto, el artículo 43 del Tratado garantiza la libertad de establecimiento y el 49 la libre prestación de servicios dentro de la Comunidad.

La citada ley, entre otras disposiciones que contienen y que afectan a la actividad de la Administración, da una nueva redacción al artículo 43 de la ley de Régimen jurídico de las Administraciones Públicas y del Procedimiento administrativo común 30/1992 de 26 de noviembre cuya reforma anterior fue comentada. El artículo se refiere al silencio administrativo y la nueva redacción 
corresponde a la iniciativa de un gobierno socialista, consecuencia de la democrática alternancia en el Poder.

Su primer apartado se refiere expresamente al silencio administrativo positivo: "1. En los procedimientos iniciados a solicitud del interesado, sin perjuicio de la resolución que la Administración debe dictar en la forma prevista en el apartado 3 de este artículo, el vencimiento del plazo máximo sin haberse notificado resolución expresa legitima al interesado o interesados que hubieran deducido la solicitud para entenderla estimada por silencio administrativo, excepto en los supuestos en los que una norma con rango de ley por razones imperiosas de interés general o una norma de Derecho comunitario establezcan lo contrario".

Este primer apartado del reformado artículo 43 recoge el contenido de los apartados 1 y 2 de la Ley 30/1992 incorporando, por exigencias de la Ley $17 / 2009$, la referencia a las "razones imperiosas de interés general" para determinar los supuestos en los que una norma con rango legal puede establecer silencio negativo. Se introduce, pues, un nuevo elemento que deberá condicionar las excepciones que las leyes pretendan introducir en el silencio positivo. No bastará una norma de rango suficiente - la realidad puso de manifiesto la disposición del legislador a excepcionar el silencio positivo- sino que será necesario, en el futuro, justificar que existe una razón imperiosa de interés general para hacerlo, encajando las excepciones en alguno de los supuestos del extenso concepto que contiene la Directiva.

Esta referencia obligada a las razones imperiosas de interés general queda, sin embargo, en entredicho respecto a las excepciones al silencio positivo existentes antes de la Ley 25/2009 a la vista de la literalidad de la Disposición adicional $4^{a}$ de la propia Ley. Bajo el título "Aplicación de los requisitos previstos para el silencio administrativo desestimatorio regulado en normas pre existentes", se señala:

"A los efectos previstos en el primer párrafo del artículo 43.1 de la Ley 30/1992, de 26 de noviembre, de Régimen Jurídico de las Administraciones Públicas y del Procedimiento Administrativo Común, de acuerdo con la redacción dada por la presente Ley, se entenderá que concurren razones imperiosas de interés general en aquellos procedimientos que, habiendo sido regulados con anterioridad a la entrada en vigor de esta Ley por normas con rango de ley o de Derecho comunitario, prevean efectos desestimatorios a la falta de notificación de la resolución expresa del procedimiento en el plazo previsto". 
En realidad, así entendidas las razones imperiosas de interés general, no se producía innovación ni avance sobre la situación anterior a la transposición de la Directiva. Dicho castizamente, para ese viaje no hacían falta estas alforjas.

No parece que se cumpliese con lo que se dice en el preámbulo de la ley:

“... para alcanzar el objetivo de reformar significativamente el marco regulatorio no basta con el establecimiento de los principios generales que deben regir la regulación actual y futura de las actividades de servicios, sino que es necesario proceder a un ejercicio de evaluación de toda la normativa reguladora del acceso a las actividades de servicios y de su ejercicio, para adecuarlos a los principios que dicha Ley -se refiere a la 17/2009- establece".

Más que una disposición adicional debería tratarse de una disposición transitoria que podría tener sentido en tanto no se llevase a cabo la citada evaluación. Es lo que sugiere la aprobación posterior de la ley 2/2011 de 4 de marzo, de Economía Sostenible. Su artículo 40 tiene como título "ampliación del silencio positivo", en el que se prevé que en el plazo de tres meses se acordaría un proyecto de ley "de modificación del sentido del silencio administrativo en los procedimientos que no se consideren cubiertos por razones imperiosas de interés general".

El cumplimiento de ese propósito se llevó a cabo por Real Decreto-ley 8/2011, de 1 de julio, de largo enunciado, que tiene que ver con medidas para combatir la crisis económico-financiera. Su artículo 26 se inserta en una sección relativa a la "modificación del sentido del silencio administrativo en determinados procedimientos" y con remisión a un largo anexo dispone que, en los procedimientos en él incluidos, el silencio administrativo tendrá un sentido positivo, estimatorio de la solicitud realizada por el particular. Como especifica el titular del anexo, en los procedimientos relacionados se pasa del silencio negativo al positivo.

La redacción del Decreto-ley produce perplejidad. La enumeración de esos procedimientos estaría introduciendo dudas acerca de la pretendida generalidad del silencio administrativo positivo. El sistema de lista es el adecuado cuando se trata de reflejar lo contrario. Los supuestos incluidos en la lista constituirían la excepción. La confusión acerca de cual es la mens legislatoris se aumenta a la vista de la disposición adicional cuarta en la que se recogen tres procedimientos relativos a productos dietéticos, en los cuales el silencio se entiende negativo.

Existe una contradicción metodológica. El silencio positivo si se configura 
como la regla general exigiría obviamente enumerar los supuestos en los que el silencio se entienda como negativo. Por el contrario, si éste es la regla general, el positivo debería constar en las correspondientes relaciones. El legislador utiliza los dos criterios. En realidad se encuentra condicionado por su posición previa de política legislativa de otorgar la preferencia al silencio positivo.

Con ocasión de la crisis económica, el criterio de lista para el silencio positivo se ha utilizado en el Real Decreto-ley 4/2012 de 24 de febrero (art. 4) respecto de la no emisión en plazo de la calificación individual solicitada por un contratista de obras, suministro o servicios a un ente local para el reconocimiento de una deuda por este, con el objeto de obtener su pronto pago acogiéndose al plan financiero previsto a ese efecto por el Gobierno.

La realidad confirma que no es sostenible el silencio administrativo positivo como regla general. Es una contradicción con la existencia de listas con ese efecto Los casos tasados de silencio positivo inducen a sostener que los no previstos como tales lo son de silencio negativo. Volveríamos así a la postura inicial, invirtiendo la generalidad del silencio a favor del negativo. ${ }^{20}$

\section{UNA CONSTRUCGIÓN PROCESALISTA DEL SILENGIO ADMINISTRATIVO}

La construcción jurídica del silencio administrativo, sobre todo del negativo o desestimatorio, está condicionada por su referencia al contencioso-administrativo y éste, a su vez, por la del acto administrativo, trátese de su revisión o del enjuiciamiento de una pretensión con ocasión de un acto administrativo. La referencia al acceso al contencioso es esencial, pero no lo es la que concierne a la necesidad de una ficción de acto o, de un modo más expresivo, al contrasentido de un acto ficticio en el caso del silencio negativo o de un acto presunto en el del positivo.

Los efectos de la inactividad formal de la Administración, en que consiste el silencio administrativo, se producen simplemente por la ley. El transcurso del tiempo previsto para que la Administración responda a la petición del particular es un simple requisito procesal para que pueda interponerse el correspon-

\footnotetext{
${ }^{20} \mathrm{El}$ anteproyecto de ley de transparencia reconoce el silencio negativo: transcurrido un mes desde la petición sin notificar la resolución expresa se entiende desestimada la petición (artículo 17). Antes de interponer recurso contencioso-administrativo podrá presentarse con carácter potestativo reclamación ante la agencia estatal de transparencia, evaluación de las políticas públicas y de la calidad de los servicios en el plazo de un mes "desde que se produzcan efectos del silencio administrativo (artículo 21,4).
} 
diente recurso contra la Administración cuando el sentido legal del silencio sea negativo. No existe necesidad alguna de inventarse la ficción de un acto. Se recurre la inactividad y se solicita, con ocasión de ella, el reconocimiento de lo solicitado.

Ni siquiera, teóricamente, sería necesario que la Administración dictase un acto expreso, aceptando o no la solicitud del particular. En el caso de conformidad con la pretensión del particular la Administración simplemente se allanaría en el proceso dándose éste por terminado. Si fuese disconforme, entendiendo que lo pedido por el particular no debería estimarse, es cierto que se privaría inicialmente de una motivación del acto expreso, pero se subsanaría en el trámite de conclusiones, para cuya formulación el demandante habría ya conocido los motivos expuestos por la Administración en la contestación a la demanda. Bien es verdad que la desigual posición del particular resultaría incrementada con la reforma en 2011 del régimen de la prueba que no solo ha de pedirse en la demanda, sino que en ella han de expresarse los puntos de hecho sobre los que ha de versar y los medios que se propongan (art. 60,1 LJCA).

La obligación de dictar un acto expreso cumple con la finalidad moralizadora o de buena administración, aunque no es el único medio para conseguirla; debería generar responsabilidad ${ }^{21}$. Corresponde al interés del particular esperar o no a que se produzca el acto expreso para interponer el recurso. En todo caso, sea o no obligatoria la producción de un extemporáneo acto expreso, la Administración debería cargar con las costas del proceso cuando la sentencia le fuese adversa o cuando se produzca una satisfacción extraprocesal o un allanamiento.

La ficción del acto ha dado lugar a posiciones diferentes respecto del plazo para recurrir. En contra se ha pronunciado el Tribunal Constitucional:" el ciudadano no puede estar obligado a recurrir en todo caso so pretexto de convertir su inactividad en el consentimiento de un acto administrativo en realidad no producido" (STC 179/2003 de 2 de octubre). El derecho a la tutela judicial efectiva permite al particular esperar a que se dicte un acto expreso. No existiría plazo para interponer el recurso evitándose así que la Administración se coloque en mejor situación que si hubiese cumplido con todos los requisitos legales (STC 239/2007 de 10 de diciembre).

${ }^{21}$ En esa dirección se orienta el Real Decreto-Ley 4/2012 al considerar el silencio positivo allí previsto como falta muy grave del funcionario. En la misma línea, el anteproyecto de ley sobre transparencia considera falta grave el incumplimiento de los plazos. 
La cuestión es disputada teniendo en cuenta posibles terceros interesados. Desde una concepción procesalista, resulta innecesaria la referencia a un acto presunto (artículo 46,1 LJCA), en realidad inexistente, para que se produzcan los efectos del silencio administrativo negativo.

Por lo que respecta al silencio administrativo positivo se ha sostenido, con razón, que es una técnica, no solo diferente del acto presunto, sino incompatible con él. ${ }^{22}$. Desde esa posición el efecto positivo lo otorga en realidad la ley sectorial correspondiente, ya que solo deberá operar si la petición es conforme con el ordenamiento legal. El acto presunto gozaría de la presunción de legalidad. Por eso el acto expreso, que en todo caso se exige a la Administración, solo puede ser confirmatorio en tanto concordante con el efecto positivo que el ordenamiento jurídico atribuye al silencio con motivo de la solicitud de un particular. Lo que sucede, como la jurisprudencia recaída en materia urbanística revela, por todas la citada STS de 28 de enero de 2009 en interés de la ley, es que el silencio formalmente administrativo se convierte en negativo para sorpresa del ciudadano que solicitó una licencia. La Administración no resuelve en tiempo y la desestima expresamente, entendiendo que la solicitud no es conforme al ordenamiento jurídico.

La situación del particular es doblemente desigual. Tiene que realizar una investigación del ordenamiento jurídico y sufrir las consecuencias económicas de la obra realizada al amparo del acto presunto operado por el silencio positivo. No resulta sorprendente que se postule doctrinalmente que sería mejor que la regla fuese el silencio negativo ${ }^{23}$ Las ventajas que en principio ofrece el silencio administrativo positivo quedan mermadas por la inseguridad.

El llamado acto presunto del silencio administrativo positivo carece de virtualidad si ha de subordinarse a su conformidad con el ordenamiento jurídico; no vincularía al exigido acto expreso confirmatorio. Si no se acepta como regla general aquella subordinación nos encontraríamos con posibles actos contra legem que la Administración vendría obligada a defender en un posible contencioso.

No hay necesidad de inventarse un acto presunto. Es la inactividad de la Administración la que, por virtud de la ley, permite el reconocimiento de un derecho eventualmente cuestionable en vía jurisdiccional, como sucede en el

\footnotetext{
22 Cfr. MORILLO-VELARDE, J.I., Los actos presuntos. Marcial Pons, Madrid, 1995.

${ }^{23}$ Cfr. GARCÍA PÉREZ, M, "El silencio administrativo tras la sentencia del Tribunal Supremo de 28 de enero de 2009", Anuario da Facultade de Dereito, Universidade da Coruña, 14, 2010.
} 
supuesto de inactividad material de la Administración que se examina a continuación.

El silencio positivo está configurado en favor del particular, que en este caso es el beneficiario. Pero puede que ese otorgamiento, con ocasión del silencio, afecte negativamente a terceros interesados. Aquí sería imprescindible establecer un plazo para que estos puedan recurrir en el contencioso, sin necesidad de referirse a un acto presunto inexistente.

La eficacia del silencio positivo y la eliminación de conflictos provendrán de la simplicidad, claridad y concreción de los supuestos en los que está previsto. Incluso con estas determinaciones, no es la única fórmula admisible, como la Directiva comunitaria de servicios testimonia.

La perspectiva procesal que aquí se adopta sería equivalente a la reacción contra la inactividad material de la Administración en cuanto no presupone un acto contra el que recurrir, pero no en cuanto a generar una pretensión de condenar a dictar un acto ${ }^{24}$ En el caso del silencio negativo el interesado tiene otras opciones, sin necesidad de reclamación alguna a la Administración. En el del silencio positivo es suficiente con una reclamación no configurable como recurso administrativo. ${ }^{25}$

\section{LA INACTIVIDAD MATERIAL DE LA ADMINISTRACIÓN}

La inactividad material de la Administración no hace referencia a la falta de respuesta ante una petición que ha iniciado un procedimiento y que la Administración ha de resolver. La inactividad de la Administración viene relacionada con el incumplimiento de algo establecido en la norma, pasividad que perjudica a los particulares. No existe un previo acto administrativo, ni expreso, ni presunto, contra el que recurrir judicialmente. Uno de los esfuerzos realizados, deudores de la superada concepción del contencioso administrativo co-

${ }^{24}$ En sentido contrario, AGUADO I CUDOLÀ, V. Silencio administrativo e inactividad, Marcial Pons, Madrid, 2001.

${ }^{25}$ El artículo 232 del Tratado de la UE prevé un recurso por omisión, por abstenerse de pronunciarse, ante el TJCE para el que están legitimados los Estados miembros y las demás instituciones de la Comunidad así como recurso de queja, para lo que están legitimadas las personas físicas o jurídicas, "por no haberle dirigido una de las instituciones de la Comunidad un acto distinto de una recomendación o de un dictamen". En ambos casos, es necesario haber requerido previamente al Consejo o a la Comisión, por lo que aquí interesa. 
mo revisora del acto, consistió en transformar esa inactividad material en inactividad formal a la que responde el tradicional silencio administrativo. Hacía falta un acto administrativo previo y el juez no podía colocarse en la situación de la Administración, a la que no podía dar instrucciones o mandatos.

Con la pretenciosa intención de cerrar "un importante agujero negro de nuestro Estado de Derecho" y de otorgar "un arma efectiva al ciudadano para combatir la pasividad y las dilaciones administrativas", la ley reguladora de la jurisdicción contencioso-administrativa ( 29/1998 de 13 de julio) creó un recurso contra la inactividad de la Administración, dirigido a obtener una prestación material debida o la adopción de un acto expreso en procedimientos iniciados de oficio, allí donde no juega la técnica del silencio administrativo.

El artículo 29 de la LJCA, regula la acción de condena de la Administración al cumplimiento de una prestación en favor de quien tiene derecho a ella (artículo 29.1). A tenor del citado artículo el demandante podrá pretender la condena de la Administración al cumplimiento de sus obligaciones en los concretos términos en que estén establecidas en una disposición general que no precise de actos de aplicación o en virtud de acto, contrato o convenio, cuando reclamada la prestación la Administración se haya abstenido de cumplirla en un plazo de tres meses (artículos 29 y 32). Es decir, lo que el ciudadano pretende es que la Administración realice una actividad o dicte un acto que le viene impuesto en virtud de ley, de acto o de contrato.

En primer lugar, el Tribunal Supremo ha puesto el acento en la legitimación (ad causam) necesaria para plantear esta acción, exigiendo al demandante que ostente un "derecho subjetivo" definido por una norma que no necesite actos de aplicación o en un acto, contrato o convenio. Lo que no ofrece duda es que para que pueda prosperar la pretensión se necesita que la disposición general invocada sea constitutiva de una obligación con un contenido prestacional concreto y determinado, no necesitado de ulterior especificación y que, además, el titular de la pretensión sea a su vez acreedor de aquella prestación a la que viene obligada la Administración. No basta con invocar el posible beneficio que para el recurrente implique una actividad concreta de la Administración, lo cual constituye soporte procesal suficiente para pretender frente a cualquier otra actividad o inactividad de la Administración, sino que en el supuesto del artículo 29 lo lesionado por esta inactividad ha de ser necesariamente un derecho del recurrente, definido en la norma "correlativo a la imposición a la Administración de la obligación de realizar una actividad que satisfaga la prestación concreta que aquél tiene derecho a percibir, conforme a la propia disposición general" (STS de 24 de julio de 2000, RJ 2001/289). 
En segundo lugar, insiste el Tribunal Supremo en la necesidad de que la prestación exigida en vía jurisdiccional debe ser concreta. Se trata de condenar a la Administración "en los concretos términos en que estén establecidas" sus obligaciones (artículo 32.1). Es decir, los jueces y tribunales no se verán en la tesitura de tener que "sustituir" a la Administración ante su inactividad determinando el cómo, dónde o cuándo del ejercicio de una potestad administrativa, porque los términos de su cumplimiento se desprenden objetivamente de la norma, del acto, del contrato o del convenio.

El único trámite previo que establece la nueva regulación para acceder al contencioso es la "reclamación" realizada al órgano administrativo que permanece inactivo. Dicha reclamación no debe confundirse con una solicitud en sentido formal, es decir, con la forma de iniciación de un procedimiento (artículos 68 y 70 de la Ley 30/1992).

No se trata de forzar el acto administrativo como requisito previo al proceso, sino de dar la oportunidad a la Administración de actuar debidamente a través de una especie de interpellatio, que puede servir para que la Administración cumpla y no haya necesidad de llegar al proceso. La propia estructura administrativa y la eficacia de la actividad administrativa requieren esta "llamada de atención" que, en ningún caso, debe volverse contra el ciudadano diligente. Pasados tres meses desde que fuere reclamada la reclamación sin haberse obtenido la prestación, quedará expedita la vía judicial. En definitiva, un requisito procesal en la línea de lo que se ha mantenido para el silencio administrativo $^{26}$.

Lo mismo acontece en el supuesto contemplado en el apartado 2 del citado artículo relativo a la inactividad de la Administración consistente en la no ejecución de sus actos firmes. Los afectados podrán solicitar su ejecución y si ésta no se produce en el plazo de un mes podrán los solicitantes formular recurso contencioso administrativo.

\footnotetext{
${ }^{26}$ En ese sentido el artículo 232 del Tratado de la UE : el recurso ante el TJCE sólo es admisible "si la institución de que se trate hubiere sido requerida previamente para que actúe".
} 


\section{ABANDONO DEL AGTO ADMINISTRATIVO PREVIO: EL CONTROL A POSTERIORI}

Desde distintas perspectivas se ha subrayado el cambio que se ha operado en la concepción de la Administración pública. Ha pasado de ser una organización fuertemente jerarquizada, instalada en el imperio, la imposición, el privilegio a otra necesitada de la colaboración de los particulares, de la participación de éstos. No son solo razones democráticas, sino también de eficiencia, aunque también un cambio de paradigma ideológico. Para expresarlo de una manera rápida, el que va del dominio de las empresas públicas a las privatizaciones.

El cambio puede referirse, por ejemplo, a la terminación convencional del procedimiento administrativo que hace innecesaria una resolución, a los contratos público-privado pensados fundamentalmente para la construcción de grandes y complejas infraestructuras, o a ese nuevo y actual mundo de la regulación económica. El acto administrativo como decisión exécutoire, deja paso en ocasiones a la recomendación ${ }^{27}$, el soft lawe, ${ }^{28} \mathrm{o}$ a una comprobación a posteriori de la actuación de los particulares. La Administración, por decirlo de un modo gráfico, se retranquea. No abre con su actuación el partido, sino que vela por que se cumplan las reglas de juego que corresponden, por ejemplo, al mercado. Esto es lo que persigue la Directiva de la Unión Europea sobre servicios anteriormente citada.

Desde una perspectiva institucional se trata de eliminar las barreras que obstaculizan el desarrollo de las actividades de servicios entre los Estados y en definitiva de acuerdo con el artículo 2 del Tratado promover "un desarrollo armonioso, equilibrado y sostenible de las actividades económicas en el conjunto de la Comunidad".

\footnotetext{
${ }^{27}$ Entre los actos de las instituciones europeas junto a los que pueden ser controlados por el TJCE las decisiones que se corresponden a la categoría del acto administrativo- se citan las recomendaciones (artículo 230 del Tratado de la UE).

${ }^{28}$ Cfr. Real Decreto-ley 6/2012 de 10 de marzo en el que se incluye como anexo un código de buenas prácticas para la estructuración viable de las deudas con garantía hipotecaria sobre la vivienda habitual. No es imperativo, pero ha sido aceptado por las entidades financieras, porque lo contrario podría acarrearles un efecto negativo para su imagen en el mercado basado en la competencia, sin descontar la presión social y mediática. Se pretende que sea obligatorio para las entidades intervenidas con capital del FROB
} 
Según la propia declaración de la Directiva la creación de un mercado competitivo de servicios es esencial para fomentar el crecimiento económico y la creación de puestos de trabajo en la Unión Europea. Se propone suprimir las barreras para la circulación transfronteriza de servicios, consistentes en un exceso de trámites administrativos con la consecuente inseguridad jurídica, y en vencer la falta de confianza o la reticencia mutua de los Estados miembros.

La Directiva se presenta como una pieza clave en la política comunitaria de impulso económico y consolidación del mercado interior de acuerdo con la estrategia de Lisboa del año 2000. Se trata, en definitiva "de crear un entorno regulatorio más favorable y transparencia en el desarrollo de las actividades de servicios en el ámbito comunitario". Transparencia e información que proporcionan a los consumidores más posibilidades de elección y precios más bajos, de acuerdo con la filosofía que preside toda la actuación de la UE, volcada en el mayor protagonismo de la sociedad frente a la intervención del Estado, reducida a lo que sea necesario.

Se trata de que los prestadores de servicios puedan establecerse libremente en cualquier país o prestar un servicio en otro país sin necesidad de establecerse en él, de acuerdo con sus personales preferencias y estrategias.

Los objetivos de la Directiva podrían resumirse en los siguientes: favorecimiento de la libre circulación de servicios, simplificación de procedimientos, mejora de la calidad de los servicios, reforzamiento de los derechos de los destinatarios de servicios y cooperación administrativa y convergencia entre los Estados miembros.

A los efectos de la exposición es suficiente referirse al cambio de orientación en la intervención administrativa que conlleva el uso limitado o abandono de la autorización como acto previo. La regla general es la no utilización del régimen de autorización. La regla excepcionalmente, y por tanto de interpretación restrictiva, por "razones imperiosas de interés general -se repite en numerosas ocasiones- puede dejar de ser cumplida". La Directiva se encarga de ilustrar qué se entiende por interés general, un concepto jurídico indeterminado que puede convertirse en una válvula de escape del sistema.

Según el considerando 40 de la Directiva, de acuerdo con la jurisprudencia del Tribunal de justicia, abarca al menos los ámbitos siguientes: orden público, seguridad pública y salud pública, objetivos de política social, protección de destinatarios, del consumidor, protección del medio ambiente y del 
entorno urbano incluida la planificación urbana y rural, seguridad vial, entre otros de una enumeración amplia que hace relativamente flexible la aceptación del principio.

La Directiva fue transpuesta sucesivamente en la Ley 17/2009 de 23 de noviembre (la ley paraguas) y la de 25/2009 de 22 de diciembre (ley ómnibus).La exposición se ceñirá a ellas en cuanto que han modificado preceptos significativos de la Ley 30/1992 de Régimen jurídico de las Administraciones Públicas así como de la Ley 7/1985 de 2 de abril sobre bases de Régimen local. Por decirlo de una manera rápida, se pretende pasar de poner el acento en el acto administrativo previo, el control a priori, a situarlo en la declaración del particular con un control a posteriori. Se pretende con ello, al menos como principio, cambiar la cultura arraigada en la Administración Pública. Bien es verdad que algunas de las novedades, como postular el mínimo de intervención administrativa pública y su carácter proporcional, lucían en la legislación local de 1955, como ocurre también con otra de las medidas de simplificación administrativa -la ventanilla única- que figuraba con otra expresión en la ley de Procedimiento administrativo de 1958.

En ese sentido se orienta el nuevo artículo 39 bis de la Ley 30/1992 relativo a principios de intervención de las Administraciones Públicas para el desarrollo de una actividad, citado con anterioridad. Se pretende sustituir la autorización por la declaración responsable y la comunicación previa.

La Ley 17/2009, de 23 de noviembre, sobre el libre acceso a las actividades de servicios y su ejercicio, define en el art. $3.9^{\circ}$, lo que se entiende por "declaración responsable":

"El documento suscrito por la persona titular de una actividad empresarial o profesional en el que declara, bajo su responsabilidad, que cumple con los requisitos establecidos en la normativa vigente, que dispone de la documentación que asi lo acredita y que se compromete a mantener su cumplimiento durante su vigencia".

Paradójicamente la citada Ley 17/2009, no incluye el concepto de "comunicación previa" en las definiciones contenidas en el art. $3^{\circ}$, aunque la cita permanentemente, siendo este el acto mediante el cual el prestador de servicios comunica a la Administración su intención de iniciar una determinada actividad de prestación de servicios. Esta omisión se ve paliada al introducir su definición en el ordenamiento jurídico estatal el art. 71 bis $2^{\circ}$ de la Ley 30/1992, de 26 de noviembre, en la redacción otorgada por la Ley 25/2009, que dispone: 
"A los efectos de esta Ley, se entenderá por comunicación previa aquel documento mediante el que los interesados ponen en conocimiento de la Administración Pública competente sus datos identificativos y demás requisitos exigibles para el ejercicio de un derecho o el inicio de una actividad, de acuerdo con lo establecido en el artículo 70.1".

Cabe destacar que esa mayor agilización administrativa y supresión de trámites burocráticos tiene su reflejo jurídico en la circunstancia de que tanto las declaraciones responsables como las comunicaciones previas supondrán, con carácter general, "el reconocimiento o ejercicio de un derecho o bien el inicio de una actividad, desde el día de su presentación, sin perjuicio de las facultades de comprobación, control e inspección que tengan las Administraciones Públicas".

Esa labor de comprobación ex post, que sustituye al tradicional control autorizador ex ante, determinará precisamente que la "inexactitud, falsedad $\mathrm{u}$ omisión, de carácter esencial, en cualquier dato, manifestación o documento" que las acompañe o su no presentación, "determinará la imposibilidad de continuar con el ejercicio del derecho o actividad afectada desde el momento en que se tenga constancia de tales hechos, sin perjuicio de sus responsabilidades penales, civiles o administrativas a que hubiera lugar" (art. 71 bis $4^{\circ}$ ).

En principio, este sistema está pensado a favor del ciudadano, pero puede convertirse en adverso. De un lado, se habla de inexactitud u omisión esencial; quizá la falsedad en algo que no sea esencial resulta dificil. El sistema depende de la eficacia de lo dispuesto en el apartado 5 de ese nuevo artículo 71 bis: que las Administraciones tendrán permanentemente publicados y actualizados modelos de declaración responsable y de comunicación previa, los cuales se presentarán de forma clara e inequívoca.

La cuestión estriba en comprobar si existe más seguridad jurídica con un acto previo, perfectamente identificado, del que se responsabiliza la Administración o con la situación ahora prevista que está pendiente de una espada de Damocles: la decisión de la Administración como consecuencia de una comprobación posterior.

En el caso de la comunicación previa todo queda al albur de la posterior comprobación que puede llevarse a cabo cuando la actividad se haya iniciado. Por eso, desde el punto de vista de la seguridad jurídica, se plantean serias dudas acerca de la ventaja de esta fórmula que se presenta como revolucionaria.

Al no existir un acto administrativo previo la resolución de la Administración, consecuencia del control, no puede consistir en una revocación de algo 
que no ha otorgado. Es la constatación de que la comunicación previa o la declaración responsable no son conformes a Derecho. Y se declara que no puede continuarse en el ejercicio del derecho a la actividad afectada desde que se tenga constancia de la inexactitud, falsedad u omisión de carácter esencial. Más aún, la Administración puede obligar al interesado a restituir la situación jurídica al momento previo al reconocimiento o ejercicio del derecho o al inicio de la actividad correspondiente.

Demasiadas posibilidades de actuación de la Administración que hace incierta la ventaja para el particular, que debe arrostrar el riesgo, sin perjuicio de que recurra si no está de acuerdo con la resolución de la Administración. La inseguridad aumenta si la Administración Pública no da suficientes garantías de que ateniéndose el particular a los modelos oficiales no existirá una declaración de ilegalidad de la actuación.

El cambio que ha originado la transposición de la Directiva de servicios queda patente en la modificación de la ley reguladora de las bases de Régimen local. Su artículo 84, frente a la disposición anterior de que un medio de intervenir la actividad de los ciudadanos es el sometimiento a previa licencia y otros actos de control preventivo, en la nueva redacción añade: "No obstante, cuando se trata del acceso y ejercicio de actividades incluidas en el ámbito de aplicación de la Ley 17/2009 de 23 de diciembre sobre el libre acceso a las actividades de servicio y su ejercicio se estará a lo dispuesto en la misma -es decir- a la comunicación previa o declaración responsable y control posterior".

De otra parte, un Real Decreto de 23 de diciembre de 2009 dio una nueva redacción al apartado 1 del artículo 22 del Reglamento de servicios de las Corporaciones locales sobre apertura de establecimientos industriales y mercantiles haciendo referencia a los medios de intervención previstos en la legislación básica en materia de régimen local y en la Ley 17/2009 de 23 de noviembre sobre libre acceso a las actividades de servicio y su ejercicio.

Ha de tenerse en cuenta que el artículo $4^{\circ}$ de esta ley reconoce la libertad de establecimiento y su artículo $5^{\circ}$ establece con claridad que "en ningún caso el acceso a una actividad de servicios o su ejercicio se sujetarán a un régimen de autorización cuando sea suficiente una comunicación o una declaración responsable del prestador mediante la que se manifiesta, en su caso, el cumplimiento de los requisitos exigidos y se facilita la información necesaria a la autoridad competente para el control de la actividad".

No queda a la elección del particular elegir uno u otro sistema. Es la Administración quién tiene que decidir cuál es el aplicable. La preferencia es cla- 
ra y se corrobora al establecerse limitación al régimen de autorizaciones: los requisitos no deben ser discriminatorios, estar justificados por una razón imperiosa de interés general, proporcionado a ella, claros e inequívocos, objetivos, hechos públicos con antelación, transparentes y accesibles (art. 9).

Ni la comunicación, ni la declaración responsable son actos administrativos. Son actos de los particulares. El efecto favorable que se les reconoce dimana directamente de la norma, siendo los actos de los particulares "una carga necesaria para el despliegue de ese efecto". No existe acto presunto y, en consecuencia carece de toda justificación la obligación de que se dicte un acto administrativo confirmatorio si en el ejercicio de su actividad de control a posteriori la Administración constata que el ejercicio de la actividad declarada por el particular, iniciada o no, no es conforme a Derecho.

También es innecesaria la ficción de la desestimación por silencio. La Administración comprueba que las manifestaciones del particular no se corresponden a la veracidad de lo declarado o no están conformes con el ordenamiento jurídico. En definitiva, como se ha dicho con razón, la habilitación al ciudadano interesado "no la genera el eventual silencio de la Administración, sino la concurrencia de la voluntad de la Ley, perfectamente objetivada en esos casos, y la conducta correcta del interesado en cuanto cumplidor de los requisitos exigidos por la norma"29.

Por lo que respecta a terceros interesados, que se consideren perjudicados por la actividad amparada por los actos del beneficiario de su comunicación o declaración responsable, no deberían tener impedido el acceso a la jurisdicción contenciosa. Podría utilizarse el procedimiento previsto para los supuestos de inactividad material de la Administración, por el no ejercicio de la actividad de vigilancia que le corresponde legalmente. El tercero interesado habría de requerir a la Administración y ante su silencio o contra el acto expreso de la Administración rechazando la interpellatio podría acudir a la jurisdicción contencioso administrativa. La suspensión cautelar, de un lado, y la condena en costas de otro pueden constituir remedios para actuaciones contrarias a Derecho.

${ }^{29}$ Cfr. LÓPEZ MENUDO, F. "La transposición de la directiva de servicios y la modificación de la ley 30/1992: el régimen de la declaración responsable y de la comunicación previa”, Revista española de la función consultiva, 14, 2010. 


\section{A MODO DE CONGLUSIÓN}

La inactividad de la Administración se manifiesta de varias maneras. Una de ellas es el denominado silencio administrativo, tanto negativo como positivo, una técnica que se encuentra ligada al acto administrativo, a su vez condicionado por el entendimiento ya superado del contencioso administrativo como revisor del acto.

El control judicial se extiende a la actuación de la Administración, incluida la no actividad. Dicho con mayor precisión, se refiere al ejercicio o no ejercicio de la potestad administrativa por quien la ostente conforme a Derecho, aunque no esté integrado en la Administración.

Los efectos que se pretenden con el silencio administrativo pueden conseguirse sin necesidad de crear ninguna ficción o presunción de actos.

La inexistencia de un acto no impide tampoco que sea recurrida la inactividad material de la Administración. En ambos casos se trata del no ejercicio debido de una potestad.

Lo mismo sucede con el no ejercicio del control a posteriori, cuando se ha prescindido del acto de intervención previo por el ordenamiento jurídico.

Los plazos para que el particular pueda recurrir por la inactividad de la Administración ante una solicitud del particular son meros requisitos procesales.

La intención de establecer el silencio administrativo positivo como regla general ha resultado un fracaso. Habría que volver a la regla general del silencio administrativo negativo.

La lucha contra el no cumplimiento de la Administración de responder en tiempo a las solicitudes de los particulares, que es contrario a una "buena administración", derecho fundamental en la UE, no se satisface con dictar un acto expreso, debería generar la responsabilidad correspondiente. La Administración, al menos, debe cargar con las costas procesales en caso de sentencia adversa, satisfacción extraprocesal o allanamiento.

La exigencia de un acto previo para reconocer el ejercicio de un derecho no tiene por qué ser necesaria. En esa línea se orienta el Derecho comunitario de acuerdo con requerimientos de una economía de mercado. De otra parte, la exigencia de una autorización ha acreditado la inoperancia del silencio admi- 
nistrativo positivo, ${ }^{30}$ que no es susceptible de aplicación a derechos fundamentales según lo expresado en la Constitución.

La actividad de la Administración debe ser reorientada de acuerdo con los principios propios de un Estado democrático de Derecho en la procura de los intereses generales, cuyo servicio es la razón de ser de la Administración Pública.

La información adecuada, la publicidad, la transparencia, favorecidas por los medios de las nuevas tecnologías, son indispensables para que funcione el sistema, a lo que ayuda una cultura democrática asumida por los ciudadanos, indispensable para la efectividad de la comunicación y declaración responsable, como sustitutivos del acto administrativo.

El Derecho administrativo, en definitiva, no ha de limitarse al control de las potestades de la Administración, sino que debe atender también a que sus estructuras y procedimientos garanticen eficientemente las libertades y derechos de los ciudadanos.

${ }^{30}$ Cfr. MARTIN MATEO, R. "Silencio administrativo y actividad autorizante" RAP, 48, 1965. 